\title{
LOS BANCALES EN LAS MONTAÑAS ESPAÑOLAS: UN PAISAJE ABANDONADO Y UN RECURSO POTENCIAL
}

\author{
Teodoro Lasanta \\ Instituto Pirenaico de Ecología (CSIC). Campus de Aula Dei. Apdo 13034, 50080-Zaragoza. \\ e-mail: fm@ipe.csic.es \\ José Arnaéz \\ Área de Geografía Física (DCH). Universidad de La Rioja. Edificio Luis Vives, 26004-Logroño. \\ e-mail: jose.arnaez@unirioja.es \\ Purificación Ruiz Flaño \\ Dpto. de Geografía. Universidad de Valladolid. Paseo Prado de la Magdalena, 46071- Valladolid. \\ e-mail: puriruiz@fyl.uva.es \\ Noemí Lana-Renault Monreal \\ Área de Geografía Física (DCH). Universidad de La Rioja. Edificio Luis Vives, 26004-Logroño. \\ e-mail: noemi-solange.lana-renault@unirioja.es
}

\section{RESUMEN}

Los bancales o terrazas han ocupado importantes superficies en las laderas de las montañas españolas. Diseñados y construidos para poder disponer de espacio cultivable en un relieve abrupto, su morfología y disposición condicionaba el funcionamiento hidrológico de la ladera, con incremento de las tasas de infiltración, y la reducción de los procesos erosivos. El abandono de los bancales ha desatado un conjunto de procesos (crecimiento y expansión del matorral, desmoronamiento de los muros de piedra e incremento de las tasas de erosión) que han contribuido al deterioro generalizado de estos paisajes complejos y de gran valor histórico. En este trabajo se exponen las funciones que las terrazas agrícolas han cumplido en el pasado y las que pueden desempeñar en el futuro: productiva, ambiental, cultural y estética. Se concluye que el mantenimiento o recuperación de las terrazas agrícolas debe considerarse como un objetivo prioritario, por sus beneficios económicos, ecológicos y paisajísticos.

Palabras clave: terrazas agrícolas, montaña mediterránea, paisaje de montaña, desarrollo rural, España.

Fecha de recepción: febrero 2012.

Fecha de aceptación: diciembre 2013. 


\section{ABSTRACT}

Agricultural terraces occupied important extents in the slopes of the Spanish mountains, with the aim of disposing a greater extent of arable land in areas of abrupt relief. However, the morphology and disposition of these terraces were determining factors of the hydrological behaviour of the slopes, increasing the infiltration rates and reducing erosive processes. The abandonment of agricultural terraces triggered a group of processes (growing and expansion of bush, crumbling of stone walls, and increasing of erosion rates). These features contributed to the generalized deterioration of those complex landscapes, being of a great historical value. The role of farm terraces in the past and those that can possibly represent in the future (productive, environmental, cultural and aesthetic) are discussed in this paper. As a conclusion, given the economical, ecological, and scenic benefits of agricultural terraces, their maintenance or restoration must be considered a priority objective in future.

Key words: agricultural terraces, Mediterranean mountains, mountain landscape, rural development, Spain.

\section{INTRODUCCIÓN}

Las terrazas de cultivo (bancales) constituyen un elemento esencial de los paisajes de la montaña española. Los suelos acumulados en las terrazas de cultivo fueron la base para la subsistencia de numerosos habitantes de la montaña, pero también para la creación de paisajes humanizados en muchos lugares del mundo: en la cordillera de los Andes (Inbar y Llerena, 2000), en los Himalayas (Gardner y Gerrard, 2003), en el Asia monzónica (Turkelboom et al., 2008), en Oriente Próximo (Ron, 1966), en África (Winter-Nelson y Amegbeto, 1998) y en el mundo mediterráneo (Rodríguez-Aizpeolea y Lasanta, 1992; Petanidou et al., 2008), son algunas de las áreas donde la agricultura en terrazas ha alcanzado especial significado.

En Europa las terrazas de cultivo son muy abundantes en los países que rodean el Mediterráneo: España, Italia, Grecia, Francia, Turquía, Líbano y en muchas regiones del Norte de África (Blanc, 1984; García-Ruiz y Lana-Renault, 2011). Hace pocos años, el proyecto LUCAS (Land Use/Cover Area Frame Statiscal Survey) estimó que, en los países de la UE-15, los muros de piedra de terrazas agrícolas alcanzaban una extensión lineal aproximada de 1.717.454 Km (European Commission, 2005).

En España el aterrazamiento de las laderas se remonta a la Edad del Bronce, en el segundo milenio a.C. (Asins, 2006). Desde entonces los bancales se construyeron de forma casi ininterrumpida hasta muy recientemente. La realización de análisis polínicos, estratigráficos, arqueomorfológicos e históricos muestra la construcción casi permanente y constante de bancales, con mayor concentración en las montañas de la mitad oriental. Los siglos XVIII y XIX fueron especialmente activos en la construcción de terrazas agrícolas; las crisis de la industria textil y de la ganadería trashumante obligaron a la roturación de tierras para compensar las rentas perdidas por la ganadería y la industria (Gómez Urdañez, 1987; Arnáez et al., 2011). A lo largo del siglo XX se construyen ya pocos bancales, dominando el proceso de abandono tanto de la producción como de las tareas de conservación (Lasanta, 1996). 
La construcción de terrazas no se realizó en todas las montañas españolas. En no pocos casos las laderas fueron cultivadas a partir de campos adaptados a la forma y desnivel de la vertiente (campos en pendiente), a veces con una ligera suavización del perfil de la ladera en la parte inferior. En general, estos campos pendientes coinciden con áreas de clima atlántico, como Galicia, la Cornisa Cantábrica, el tercio occidental de los Pirineos y la Sierra de la Demanda, en el Sistema Ibérico (Delgado-Viñas et al. 2010; Lasanta, 2010). Los campos en pendiente dominan también en áreas con menos precipitaciones, como el Sistema Ibérico aragonés o buena parte de las Béticas, relacionándose quizás con repoblaciones de gentes venidas del norte y noroeste de España (Anglada et al., 1980). Por el contrario, los bancales constituyen el elemento principal del paisaje en las laderas cultivadas de clima mediterráneo, estando muy presentes en el Pirineo centro oriental (Lasanta, 1989; Latron, 1991), en el Maestrazgo aragonés y castellonense (Ascaso et al., 1996; Asins, 2007), en las áreas de montaña de Alicante y Valencia (Rodríguez Aizpeolea, 1990), en Camero Viejo, Sistema Ibérico, (Arnáez et al., 1990), en algunos sectores de las Béticas (Bosque Maurel, 1968) y en la montaña balear (Grimalt et al., 1992).

A lo largo del siglo XX, y muy especialmente desde los años sesenta, la mayor parte de los bancales han dejado de cultivarse a la vez que cesaron las tareas de conservación del suelo. Por ello, muchos de los bancales sufren un proceso de deterioro muy acusado, con pérdida de suelo e invasión de matorrales de sucesión que homogeneizan el paisaje, disminuyen su calidad estética y constituyen una fuerte amenaza para la génesis y propagación de incendios (Lasanta et al., 2009a; Santana et al., 2010).

Sin embargo, los paisajes de terrazas de cultivo constituyen un recurso potencial muy interesante para el desarrollo de áreas de montaña. Estos paisajes manifiestan a la vez los modos de gestión del territorio por parte de la sociedad (paisaje cultural) y las modificaciones realizadas por el hombre en el medio físico para producir. También aportan diversidad y valor a su entorno (paisaje construido). Reúnen, pues, aspectos naturales y culturales; de ahí que el Convenio Europeo del Paisaje, firmado en Florencia (Italia) el 20 de octubre de 2000, señale que la integración de lo social con lo natural da un valor de excepción al paisaje, que constituye un recurso esencial para la actividad económica y que su protección, gestión y ordenación puede contribuir a la creación de empleo.

En este contexto, se plantea una pregunta: ¿Qué hacer con las terrazas de cultivo? Existen dos alternativas: no intervenir en el territorio y dejar que los bancales se degraden totalmente y desaparezcan del paisaje o tratar de mantener algunos de ellos. El objetivo de este trabajo es aportar información, a partir de un análisis bibliográfico, sobre las funciones que las terrazas agrícolas han cumplido en el pasado y las que pueden desempeñar en el futuro si se mantienen activas. Este último aspecto ha sido todavía poco abordado por los geógrafos, a pesar de la amplia extensión que ocupan en las montañas españolas y del interés que puede tener su conservación para el desarrollo sostenible de muchos valles de montaña.

\section{EXTENSIÓN, LOCALIZACIÓN Y TIPOLOGÍA DE LAS TERRAZAS AGRÍCOLAS}

Los bancales se construyeron en el ámbito mediterráneo para cultivar cereales, principalmente, y de forma más secundaria almendros, olivos y viñedos. En algunas ocasiones también se cultivaron hortalizas y otros frutales. Su primera función fue alimentar a la población de muchos municipios de montaña (Rodríguez-Aizpeolea y Lasanta, 1992). Solo una causa tan 
importante puede explicar la extensión que ocuparon y el enorme esfuerzo hecho por generaciones enteras para crear un paisaje excepcional. La bibliografía no es muy explícita sobre la superficie ocupada por los bancales, limitándose en la mayor parte de las ocasiones a señalar que forman parte importante o dominante del paisaje agrícola, para a continuación centrarse en cuestiones muy concretas: utilización tradicional, erosión del suelo, procesos de sucesión vegetal, paisaje, estado de conservación... No obstante, algunos trabajos han realizado una importante tarea de cartografía y cuantificación de las laderas abancaladas. Entre ellos, y sin ánimo de ser exhaustivos, pueden incluirse los trabajos de Grimalt y Blázquez (1989) sobre la Sierra de Tramuntana (Mallorca), donde las terrazas de cultivo alcanzaron 16.765 ha $(72,3 \%$ del espacio cultivado), de Rodríguez Aizpeolea (1992) sobre el municipio de la Vall d'Ebo (Alicante), donde los bancales llegaron a ocupar el 100\% (705 ha) del espacio cultivado, y de Asins (2009) que aporta una superficie de 2762 ha (100\% del espacio cultivado) en el municipio alicantino de Petrer. La información más detallada corresponde, quizás, al Pirineo Aragonés y al Sistema Ibérico riojano, donde desde mediados de los años ochenta del siglo XX, se ha estudiado el tema de los bancales desde diferentes perspectivas (ver citas en la relación bibliográfica incluida al final de este trabajo), entre las que se incluyen la extensión y representatividad de los bancales dentro del espacio agrícola (Cuadros 1 y 2 ).

En el cuadro 1 se recoge información sobre siete valles del Pirineo Aragonés. Los tres primeros (Hecho, Aragüés y Aísa) son representativos del Pirineo Occidental, con condiciones climáticas propias del clima atlántico (Creus, 1978). Los dos siguientes (Tena y Biescas) corresponden a espacios de transición, y los dos últimos (Broto y Bestué), localizados en la comarca del Sobrarbe, tienen claras influencias del clima mediterráneo en su variante continental (Creus, 1978). Estas diferencias climáticas se manifiestan en el paisaje agrícola mediante la representatividad de los distintos tipos de campos. Así, en los valles occidentales destacan los campos en pendiente, mientras que en los orientales los bancales constituyen el modelo dominante. Por su parte, en Tena y la Ribera de Biescas el paisaje agrícola es más complejo, propio de un área de transición, con una distribución equilibrada de los tipos de campos agrícolas.

Cuadro 1

EXTENSIÓN DE LAAGRICULTURA EN TERRAZAS EN ALGUNOS VALLES DEL PIRINEO ARAGONÉS

\begin{tabular}{|l|c|c|c|c|c|c|c|c|}
\hline Valle & $\begin{array}{c}\text { Llanos } \\
\text { (ha) }\end{array}$ & $\%(1)$ & $\begin{array}{c}\text { En pendiente } \\
\text { (ha) }\end{array}$ & $\%(1)$ & Bancales (ha) & $\begin{array}{c}\% \\
(1)\end{array}$ & $\begin{array}{c}\text { Total } \\
\text { (ha) }\end{array}$ & $\begin{array}{c}\% \\
(2)\end{array}$ \\
\hline Hecho & 865,2 & 14,7 & 4491 & 76,3 & 529,7 & 9 & 5886 & 25,2 \\
\hline Aragüés & 203,9 & 17,9 & 741,5 & 65,1 & 193,6 & 17 & 1139 & 15,5 \\
\hline Aísa & 193,9 & 12,5 & 1262,5 & 81,4 & 94,6 & 6,1 & 1551 & 19 \\
\hline Tena & 447,9 & 26,3 & 688 & 40,4 & 567,1 & 33,3 & 1703 & 5,7 \\
\hline Biescas & 1778,5 & 47,9 & 727,7 & 19,6 & 1206,7 & 32,5 & 3713 & 19,9 \\
\hline Broto & 497,9 & 10,7 & 916,6 & 19,7 & 3238,5 & 69,6 & 4653 & 14,8 \\
\hline Bestué & 314,6 & 16,7 & 258,1 & 13,7 & 1311,3 & 69,6 & 1884 & 18,9 \\
\hline Total & 4301,9 & 20,9 & 9085,4 & 44,3 & 7141,5 & 34,8 & 20529 & 15,9 \\
\hline
\end{tabular}

(1) Respecto al total de la superficie cultivada en cada valle

(2) Proporción que ocupó el espacio agrícola respecto a la extensión total de cada valle.

Fuente: Lasanta (1989) 
El cuadro 2 incluye cinco valles del Sistema Ibérico riojano, localizados todos ellos en el sector centro-oriental de la región, coincidiendo, a grandes rasgos, con la Sierra de Cameros (Calvo Palacios, 1977). Se observa que en el valle del Iregua (Camero Nuevo), que actúa como área de transición entre las influencias oceánicas y mediterráneas (figura 1), los bancales ocupan mucha menos superficie que en Camero Viejo (Leza, Jubera y Cidacos), donde ya no hay rasgos del clima oceánico. Por su parte, en el valle del Linares, la representación de los bancales disminuye como consecuencia de la mayor presencia de espacios llanos y de la mayor suavidad del perfil de las laderas (Maiso y Lasanta, 1990).

Cuadro 2

EXTENSIÓN DE LAAGRICULTURA EN TERRAZAS EN ALGUNOS VALLES DEL SISTEMA IBÉRICO RIOJANO

\begin{tabular}{|l|c|c|c|c|c|c|c|c|}
\hline Valle & Llanos (ha) & $\begin{array}{c}\% \\
(1)\end{array}$ & $\begin{array}{c}\text { En pendiente } \\
(\mathrm{ha})\end{array}$ & $\begin{array}{c}\% \\
(1)\end{array}$ & Bancales (ha) & $\begin{array}{c}\% \\
(1)\end{array}$ & $\begin{array}{c}\text { Total } \\
\text { (ha) }\end{array}$ & $\begin{array}{c}\% \\
(2)\end{array}$ \\
\hline Iregua & 913,4 & 8,9 & 5048,7 & 49,1 & 4314,9 & 42 & 10277 & 20,1 \\
\hline Leza & 491,8 & 4,1 & 4896,2 & 41,3 & 6478,4 & 54,6 & 11866,4 & 42,9 \\
\hline Jubera & 157,6 & 3,9 & 1858,2 & 45,2 & 2092,4 & 50,9 & 4108,2 & 35,4 \\
\hline Cidacos & 180,9 & 2,1 & 458,2 & 5,4 & 7870,5 & 92,5 & 8509,6 & 52 \\
\hline Linares & 1697 & 23,7 & 2621 & 36,6 & 2849 & 39,7 & 7167 & 43,1 \\
\hline Total & 3440,7 & 8,2 & 14882,3 & 35,5 & 23605,2 & 56,3 & 41928,2 & 34 \\
\hline
\end{tabular}

(1) Respecto al total de la superficie cultivada en cada valle

(2) Proporción que ocupó el espacio agrícola respecto a la extensión total de cada valle.

Fuente: Maiso y Lasanta (1990); Lasanta et al., (2009b)

La tipología de terrazas agrícolas en el mundo mediterráneo es muy variada, atendiendo a la litología, la disposición de los campos en las laderas, el tipo de construcción y los elementos empleados para la conservación y gestión del agua (Pérez-Cueva, 1985; Asíns, 2009). No obstante, pueden diferenciarse 4 tipos principales.

El modelo más común de terraza agrícola consiste en un rellano delimitado aguas abajo por un salto más o menos elevado. En la parte externa, el modelo más perfecto y costoso tiene un murete de piedra seca, que contribuye a frenar la tendencia natural a la caída de la tierra (figura 2). En otros bancales no se construyó el tapial, sino que un talud, recubierto por hierba o matorrales y a veces algunos árboles frutales, sirve para sujetar el suelo acumulado en la terraza (figura 3). En el Pirineo central, por ejemplo, los taludes de hierba eran segados y pastados por el ganado originando un césped con alta capacidad para sujetar el suelo (Balcells, 1985). En ocasiones las terrazas no son totalmente llanas, sino ligeramente pendientes, pudiendo contar con un murete, como resultado -casi siempre- de la limpieza de piedras en los campos, o con un talud vegetal (figura 4).

Lasanta (1990), al estudiar la distribución de los modelos de campos agrícolas en el Alto Gállego (Pirineo Aragonés), comprobó que los bancales con talud de hierba eran mayoritarios en las exposiciones umbrías, donde el ambiente húmedo favorece la formación de un césped denso. Por el contrario, los bancales con murete de piedra dominaban en las solanas. También se ha comprobado, tanto en el Pirineo como en el Sistema Ibérico, que los bancales 
Figura 1

LADERAS ABRUPTAS UTILIZADAS PARA EL APROVECHAMIENTO AGRÍCOLA

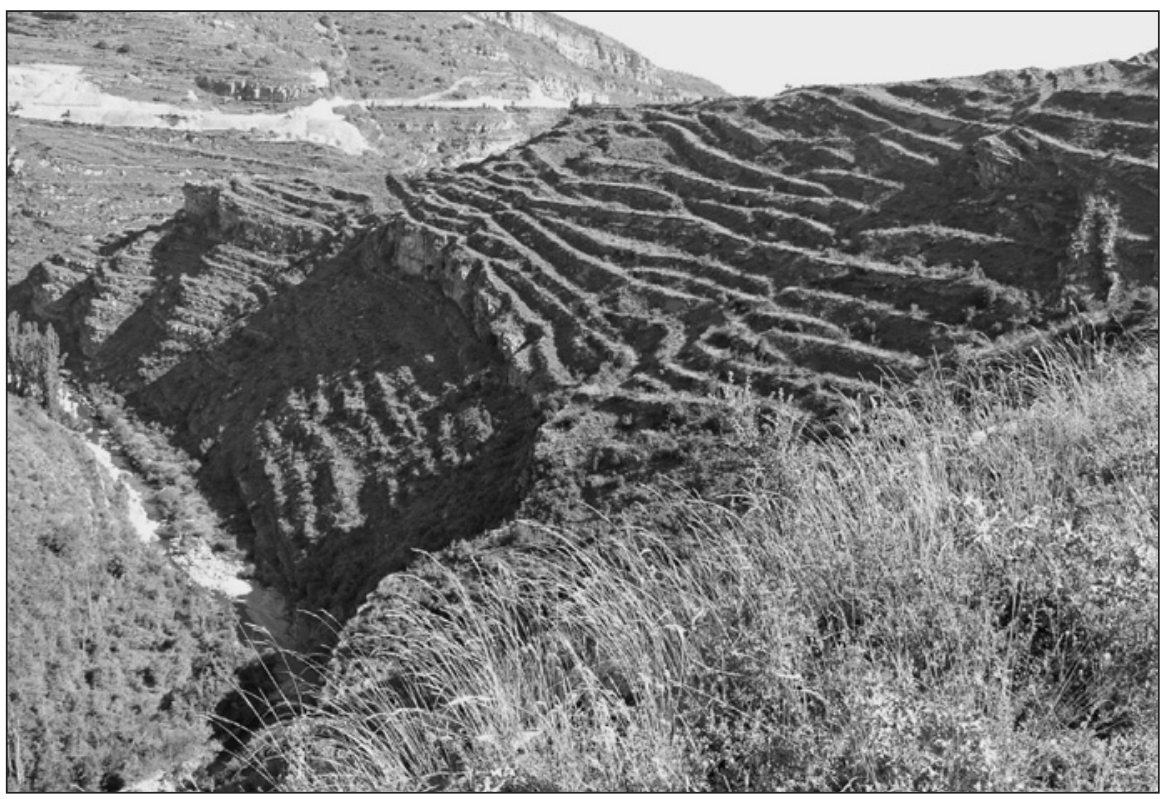

Soto en Cameros, valle del Iregua, Sistema Ibérico noroccidental, La Rioja. Foto: Luis Ortigosa.

Figura 2

MODELO DE TERRAZAAGRÍCOLA CON FAJA DE CULTIVO LLANA Y MURETE DE PIEDRA SECA

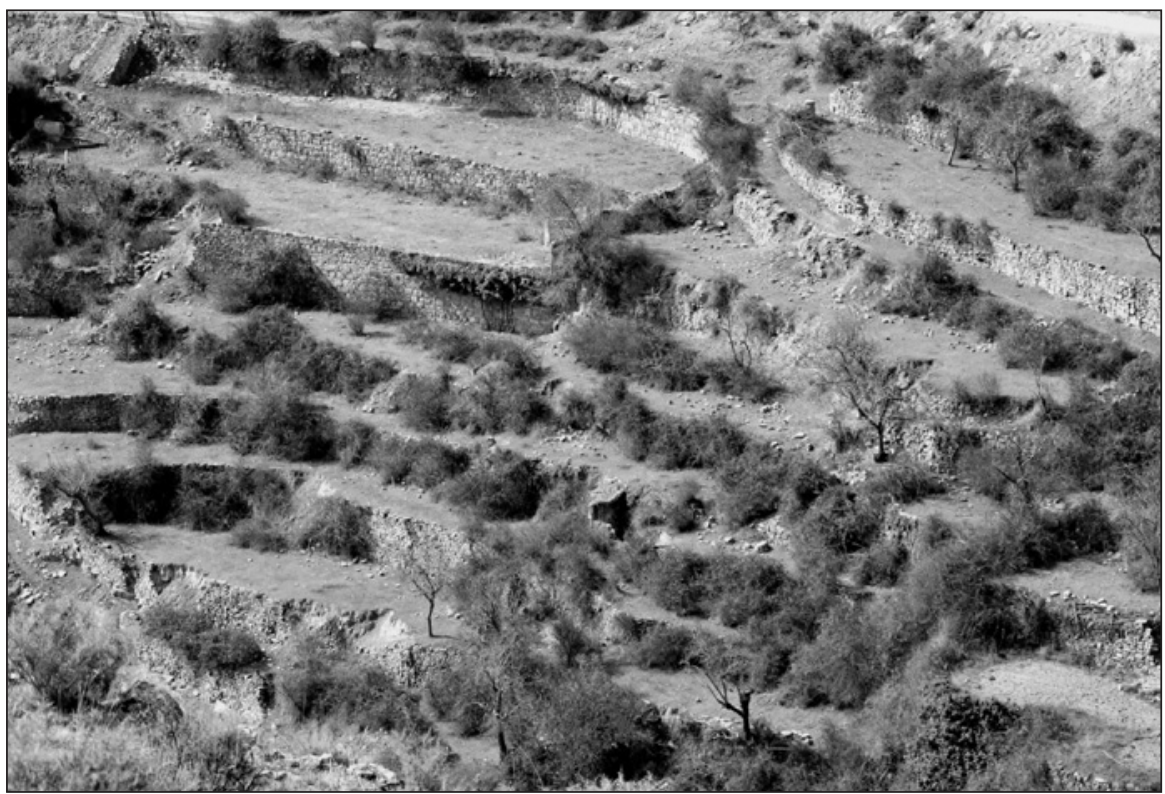

San Vicente de Munilla (La Rioja), valle del Cidacos. Foto: Luis Ortigosa. 
Figura 3

LADERAS DE BANCALES CON TALUD VEGETAL DE HIERBA Y MATORRALES

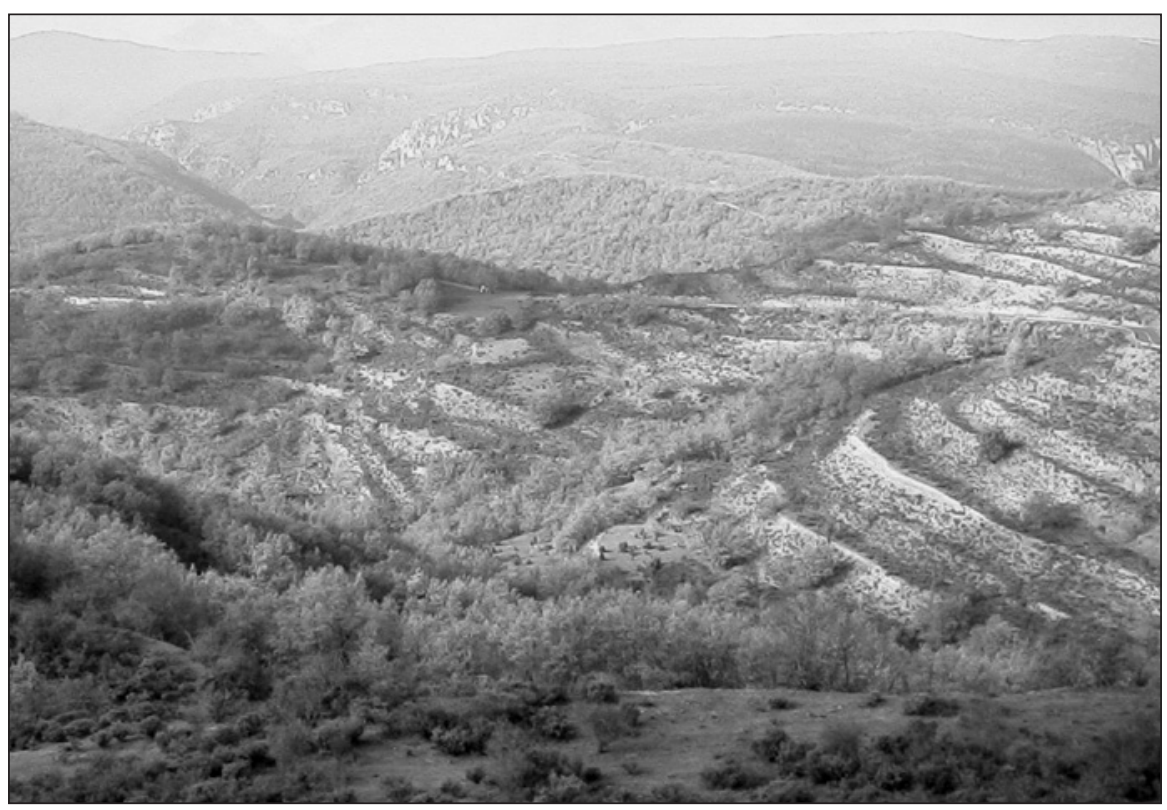

Almarza, valle del Iregua en La Rioja. Foto: Luis Ortigosa.

Figura 4

MODELO DE BANCALES CON TERRAZAS AGRÍCOLAS ABANDONADAS DE LIGERA PENDIENTE

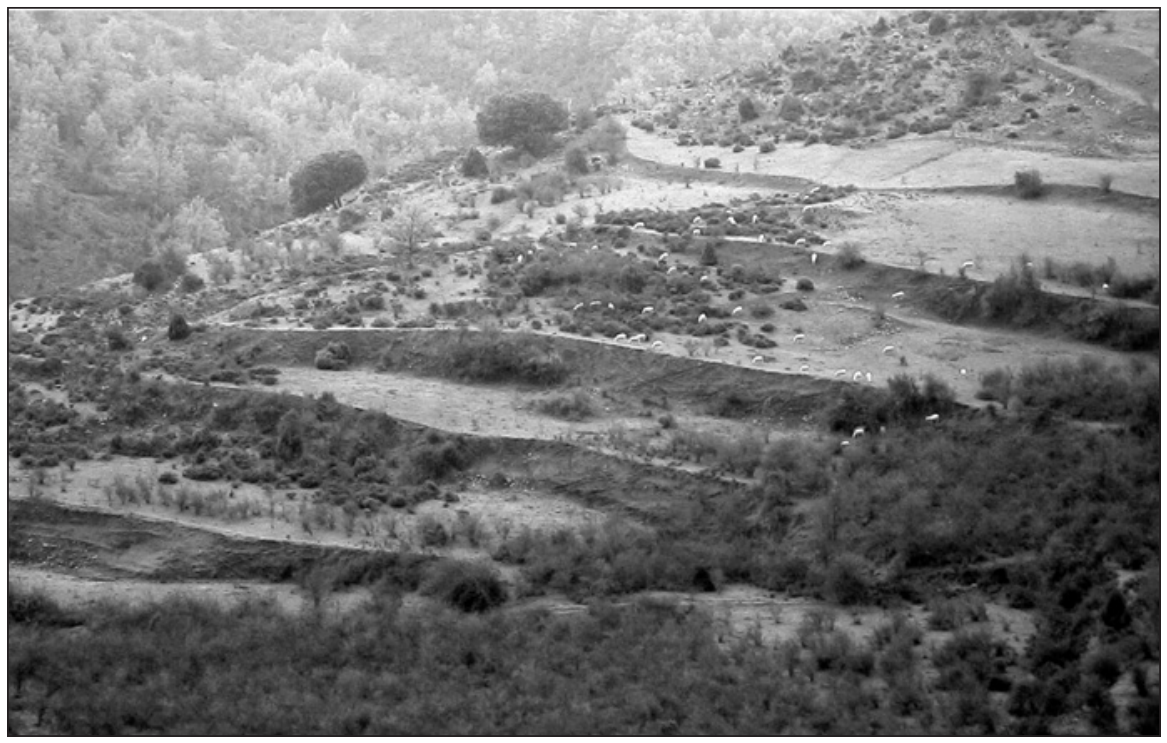

Almarza, valle del Iregua en La Rioja. Foto: Luis Ortigosa. 
que requerían mayor inversión de trabajo tendían a localizarse en las proximidades de los pueblos o en los suelos más fértiles, mientras que la calidad de la construcción disminuía a medida que se alejaban de los pueblos o los suelos eran menos profundos y más pedregosos (Lasanta, 1997).

Los bancales también se diferencian por la anchura de su terraza y la altura del salto. Estos elementos están directamente relacionados con la pendiente de la ladera. En general, las laderas de fuerte pendiente cuentan con bancales muy estrechos, que siguen las curvas de nivel, y saltos de varios metros. En cambio, en suaves concavidades la superficie de los bancales puede ser mucho mayor y los saltos de separación de menor altura (Arnáez et al., 1993).

\section{IMPLICACIONES DEL ABANDONO DE LAS TERRAZAS AGRÍCOLAS}

A partir de mediados del pasado siglo se asiste al abandono de numerosas laderas abancaladas. Y su paisaje, consecuencia del aprovechamiento tradicional de la pendiente, corre el riesgo de desaparecer. Lasanta (1989) señala que los bancales del Pirineo resistieron bien la primera fase de abandono, pero se dejaron de cultivar masivamente en los años sesenta y setenta del siglo XX, por las dificultades para su trabajo con maquinaria agrícola. Algo parecido ocurrió en el Sistema Ibérico riojano, donde sólo el 5\% de los bancales se mantienen en cultivo, casi siempre de almendros y olivos (Ruiz Flaño, et al., 2009). Ruecker et al. (1998) señalan que en el Maestrazgo (Castellón y Teruel) las terrazas de cultivo representan el 21\% de la superficie total, estando en más del $90 \%$ abandonadas en la actualidad. Lesschen et al. (2008) señalan que la Cuenca de Cárcavo (Murcia) los bancales ocuparon el 39\% de la superficie agrícola, estando en la actualidad abandonados; Grimalt y Blázquez (1989) ponen de relieve que en la Sierra de Tramuntana el 28,5\% de la superficie abancalada ya se había dejado de cultivar antes de 1979.

Con el cese del cultivo se introduce una nueva dinámica en la que participan, por un lado, los procesos naturales de recolonización vegetal y, por otro lado, los de erosión. El comportamiento de ambos da lugar a situaciones muy diversas en función de las condiciones ambientales y de la gestión post-abandono. Pero en la mayoría de las laderas se asiste a procesos de sucesión vegetal con avance de matorrales, que tienden a homogeneizar el paisaje y a disminuir la diversidad biológica (Jiménez Olivenza, 1989-90; Rodríguez Aizpeolea et al., 1991; Tatoni et al., 1994; Poyatos et al., 2003; Gallego-Fernández et al., 2004; Errea et al., 2009). El pastoreo del ganado ejerce una función importante en la evolución de la cubierta vegetal. Si la presión es la adecuada, se mantiene un buen cubrimiento de herbáceas, de pasto productivo, que además contribuye a potenciar la estética del paisaje. Pero esto no es lo habitual ahora en las montañas españolas: la disminución de los censos, el cambio de razas y la escasa vigilancia por parte de los pastores conducen frecuentemente a la concentración del ganado en unos puntos concretos (proximidades de establos, pueblos, agua y pastos más productivos) y a la subutilización o abandono de la mayor parte del territorio. En estas últimas zonas, el pasto se embastece y las herbáceas dejan paso a los arbustos (Ascaso et al., 1996; Lasanta, 2009), como se aprecia en la Figura 5, con la consiguiente pérdida de productividad, incremento del riesgo de incendios (Vicente-Serrano et al., 2000) y degradación del paisaje (Lasanta et al., 2006). Jiménez-Olivenza y Porcel (2008) señalan que con el abandono de las 
Figura 5

EMBASTECIMIENTO DEL PASTO DE LOS BANCALES

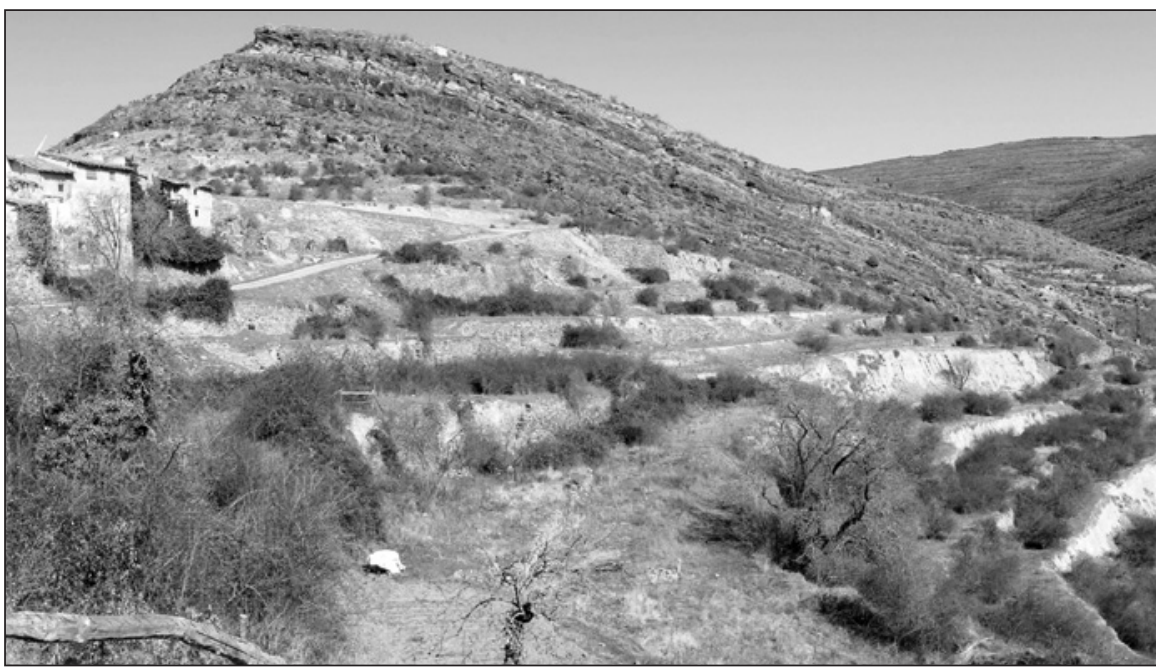

Diferentes especies de arbustos y otras plantas herbáceas por abandono ganadero. San Vicente de Munilla. Foto: Luis Ortigosa

Figura 6

DESPRENDIMIENTOS DE LOS MUROS DE PIEDRA SECA EN BANCALES AGRÍCOLAS

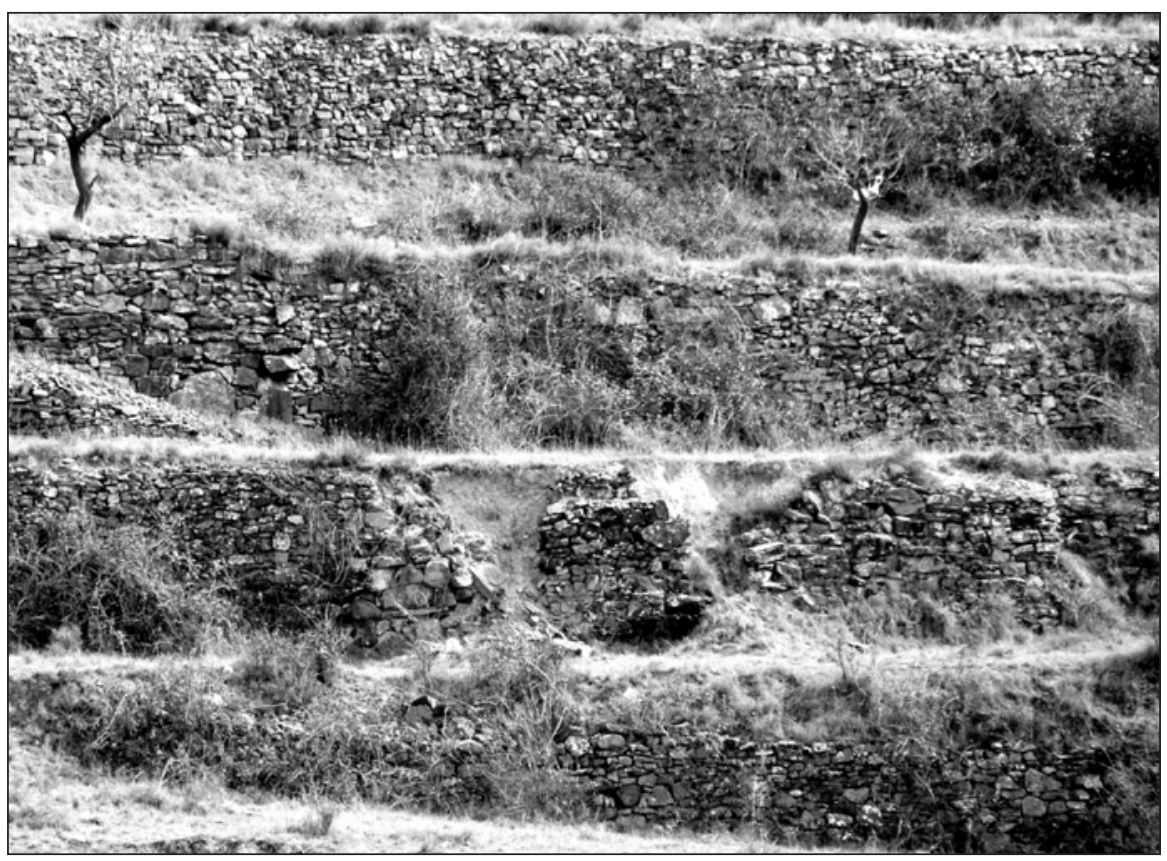

Peroblasco (Munilla), valle del Cidacos, La Rioja. Foto: Luis Ortigosa 


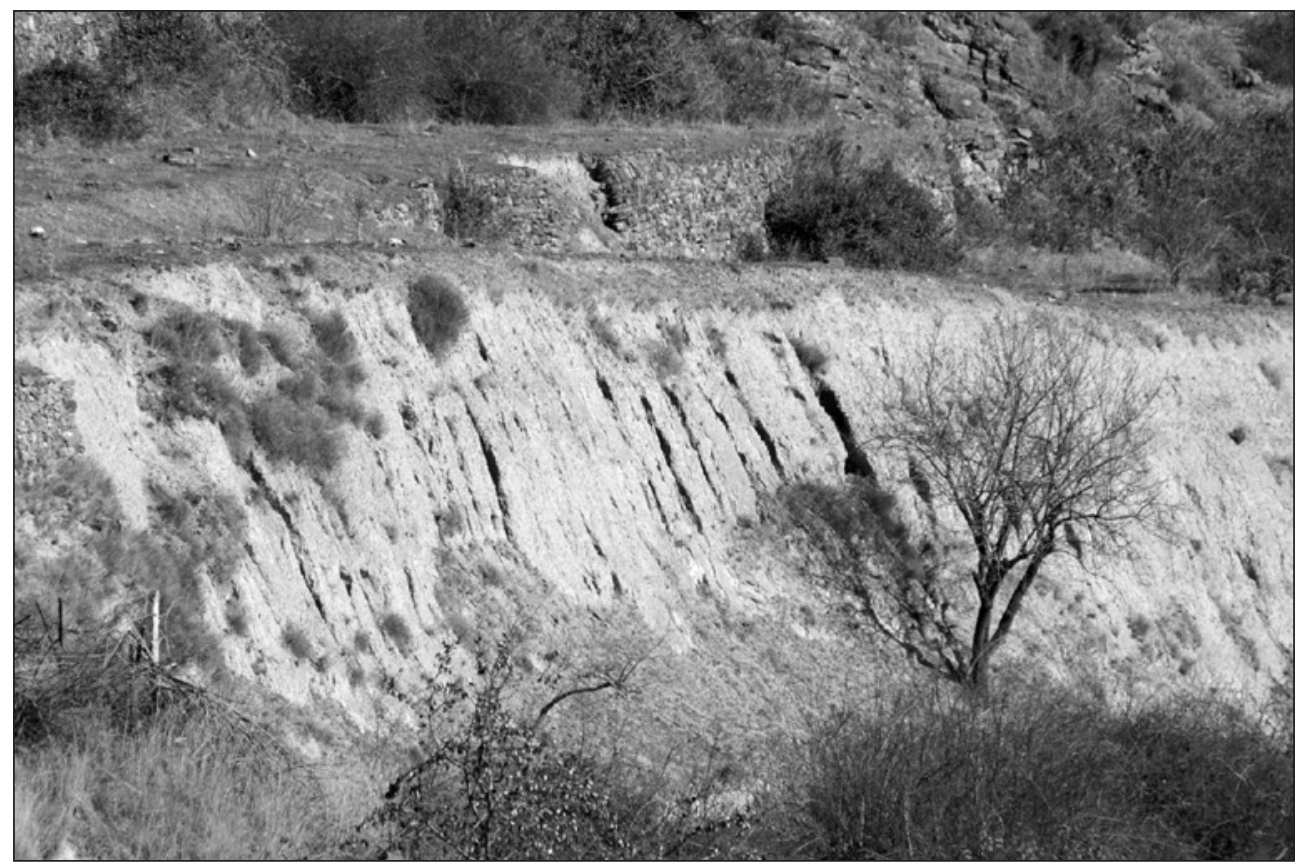

Munilla, valle del Cidacos, La Rioja. Foto: Luis Ortigosa

terrazas agrícolas se pierde uno de los elementos más singulares de los paisajes mediterráneos, con el consiguiente empobrecimiento ecológico y cultural.

Por otro lado, se observa que en la mayoría de los bancales se instalan diferentes procesos erosivos ligados a la escorrentía superficial y subsuperficial, si bien el colapso de los muros (Figura 6) por deslizamientos suele ser el proceso que acarrea más pérdidas de suelo y el que sirve de inicio para la génesis de otros procesos (Lasanta et al., 2001; Dunjó et al., 2003; Arbelo et al., 2006; Arnáez et al., 2009). En algunos bancales ligeramente inclinados y sin denso cubrimiento vegetal, junto a los desprendimientos, actúa también la escorrentía superficial (Rodríguez Aizpeolea, et al., 1991; Arnáez et al., 1993; Cerdà, 1994). Ésta se manifiesta en la superficie del bancal por medio de pequeños rodales de suelo desnudo, con aumento notable de la pedregosidad, o en los pequeños sectores de fuerte pendiente situados al pie del muro de piedra. En algunos ambientes muy degradados se han detectado procesos de incisión. En la figura 7 podemos observar las rigolas y cárcavas en el talud de un bancal (Pérez Cueva y Recatala, 1990).

La erosión del suelo tras el abandono de los bancales tiene mucho que ver con las modificaciones hidrológicas introducidas por el hombre en las laderas durante la fase de cultivo. Los bancales fueron construidos para favorecer la infiltración y frenar la escorrentía, lo que sin duda beneficia al régimen hídrico de las vertientes y reduce el arrastre de materiales. A cambio exige una gran inversión de trabajo para garantizar su estabilidad. Cuando se aban- 
donan, los sistemas de drenaje pierden funcionalidad facilitando la saturación del suelo y desencadenando mecanismos naturales, hasta entonces controlados por el hombre, que tratan de recuperar el perfil original de la ladera (Lasanta et al., 1996).

\section{FUNCIONES POTENCIALES DE LOS PAISAJES ABANCALADOS DE MONTAÑA}

Los paisajes de bancales, útiles en el pasado, pueden en el futuro desarrollar diversas funciones: agrícola-ganadera (productivista o utilitaria), ambiental, cultural y estética.

\subsection{Función productiva}

Ya se ha señalado anteriormente que las terrazas agrícolas se construyeron para producir alimentos. En el momento actual parece impensable su cultivo de forma masiva, ya que su configuración y morfología dificultan la mecanización de los laboreos. De ahí, que muchas de las laderas aterrazadas se hayan abandonado. Sin embargo, todavía se cultivan, sobre todo con frutales, en las Islas Baleares (Grimalt et al., 1992), en Levante (Asins, 2009) y en las montañas andaluzas (Rubio-Barquero et al., 2010). Además, de su aprovechamiento para la agricultura comercial las terrazas agrícolas también pueden ser interesantes para cultivos de elevada calidad, que requieren trabajo minucioso y manual. Mander et al. (1999) señalan que las áreas marginadas con baja intensidad de cultivos presentan un elevado potencial para la agricultura ecológica, ya que tienen baja polución y alta biodiversidad. Constituyen un espacio idóneo para alojar pequeños huertos, bosquetes experimentales, viveros sobre fruticultura de montaña, plantas medicinales, especies forestales, hongos y setas. Y también para repoblaciones arbóreas. Los resultados de las reforestaciones llevadas a cabo en Camero Viejo (La Rioja) permiten ser optimistas sobre la capacidad de los bancales para albergar distintas especies forestales; su enraizamiento y crecimiento ha sido rápido, acelerando la recuperación del arbolado y mejorando la heterogeneidad del paisaje (Palacios-Cuesta, 2009).

En otros casos, los bancales constituyen espacios idóneos para mantener cultivos como la vid, que exige suelos profundos para que sus raíces penetren y una temperatura adecuada para que la uva madure. Ambas circunstancias se consiguen con la construcción de terrazas agrícolas en laderas solanas, como se da -por ejemplo- en Galicia (Santos Solla, 1992) o en Cataluña (Cots-Folch et al., 2006), a semejanza de lo que ocurre en no pocas áreas húmedas y frías de la montaña europea (Murisier, 1981; Blanc, 1984).

Las terrazas agrícolas forman parte esencial de los circuitos de pastoreo de la ganadería extensiva. Lasanta (2009) ha comprobado que los rebaños de ganado vacuno se concentran preferentemente en los bancales próximos a los pueblos y establos, al mantener una cubierta herbácea muy apetecible por ser los últimos campos abandonados, mientras huye de las laderas de fuerte pendiente. En el territorio esta estrategia de pastoreo implica la fragmentación del paisaje, al intercalarse áreas muy visitadas por el ganado, donde se mantiene una vegetación herbácea, con otras que nunca son pastoreadas, donde avanzan los matorrales de sucesión. El resultado es un paisaje más diverso, más atractivo y en el que el riesgo de incendios es más controlable que en aquellas laderas sin aprovechamiento ganadero, donde los matorrales cubren la totalidad del territorio, originando un paisaje muy homogéneo y con elevado riesgo de incendio (Lasanta et al., 2006; Alomar y Bardi, 2007; Joy y Medrano, 2007). 


\subsection{Función ambiental}

Las terrazas agrícolas son estructuras construidas en las laderas de la montaña mediterránea para, además de disponer de espacio cultivable, favorecer la infiltración del agua y controlar la pérdida de suelo. En ambientes mediterráneos la lluvia alcanza una alta intensidad horaria, por lo que los suelos removidos pueden perderse después de algunas tormentas. Para evitar la erosión, los agricultores compartimentaron las laderas en una sucesión de rellanos y escalones que transformaban la topografía original y la distribución del suelo. En la parte más interna, la terraza cuenta con un suelo muy delgado que, en ciertos casos, puede favorecer la saturación y crear situaciones de encharcamiento temporal (Llorens et al., 1992), mientras que hacia el borde externo el espesor del suelo puede llegar a varios metros, potenciando la infiltración de la lluvia y la disponibilidad de agua en el suelo. La artificialidad de este sistema se completaba con la derivación de las escorrentías fuera de los bancales o hacia posiciones marginales, mediante sistemas de drenaje superficial y subcortical (García-Ruiz y López Bermúdez, 2009).

Mientras los campos abancalados eran cultivados, la saturación del suelo se trataba de evitar con los sistemas de drenaje ya aludidos, gracias a los cuales el agua que circulaba por las parcelas se concentraba en unos canales artificiales por los que era evacuada. Por otro lado, los bancales eran cuidados minuciosamente. Cuando se producía un desprendimiento del salto, se procedía a su rápida rehabilitación; la tierra caída a la parcela inferior era incorporada de nuevo a la cicatriz de arranque y era protegida con piedras. Si era necesario se acarreaba tierra de laderas próximas para borrar completamente las cicatrices creadas por las aguas de escorrentía (García-Ruiz et al., 1988). La efectividad del sistema fue alta, como lo demuestra el hecho de que muchos de los bancales se conserven intactos o con pérdidas mínimas de suelo. El problema viene cuando dejan de realizarse las tareas de mantenimiento de las acequias de drenaje y en los muretes de piedra, lo que propicia la activación de procesos erosivos que amenazan con la pérdida de los suelos más fértiles de la montaña.

Si bien la función ambiental básica de las terrazas fue controlar la erosión del suelo, se ha señalado también que los lomos de las terrazas, cubiertos por vegetación, han facilitado el cobijo a numerosas especies, funcionando como corredores ecológicos o green veining, contribuyendo a la conservación de la flora y fauna asociadas a la agricultura. Esta contribución es sumamente importante porque aproximadamente el 50\% de las especies europeas dependen de los hábitats agrícolas (Grashof-Bockan y Van Langevelde, 2004).

\subsection{Función cultural}

Moreira et al. (2006) incluyen a los bancales con murete de piedra entre los cuatro paisajes culturales más destacables del mundo mediterráneo. La función cultural de los aterrazamientos deriva de la técnica de construcción empleada, en la medida en que recopila el saber de los agricultores, plasmado en las laderas abancaladas desde la Edad del Bronce, y las habilidades sociales para estructurar simultáneamente unos espacios con fines productivos y de conservación (Asins, 2007). Frente a la dureza de las condiciones climáticas, la altitud y la pendiente, el agricultor tuvo que dar una serie de respuestas utilizando los recursos y 
materiales disponibles. Los bancales, como sistemas de cultivo en pendiente, constituyen un notable recurso cultural.

A todo ello se añade la labor de información que encierra un paisaje de bancales, al igual que otros muchos paisajes rurales (González Bernáldez, 1981). En un paisaje se encuentran siempre retazos de épocas distintas, superpuestos y entremezclados. La fecha de abancalamiento de una ladera informa de las necesidades de una sociedad en una época de la historia. La localización de los diferentes modelos de bancales manifiesta la discriminación espacial realizada por el hombre en función de la fertilidad del suelo y la accesibilidad. La existencia o ausencia de muretes nos anuncian las condiciones microclimáticas de cada enclave. En los muros y tapiales podemos encontrar piezas de calidad contrastada, llenas de equilibrio en dimensión y proporciones, adaptadas al medio, ajustadas a las necesidades, bien diseñadas y mejor ejecutadas. De gran mérito si tenemos en cuenta los pocos medios y las dificultades de todo tipo inherentes a su época.

Podrían sacarse muchas enseñanzas de este paisaje rural del pasado. Con los muretes de piedra se perseguía aumentar la infiltración y disminuir la erosión. Pero los constructores, también usuarios por lo general, aprovecharon las propiedades intrínsecas de la piedra seca: retención de la humedad, aireación moderada pero continua, inercia térmica con mantenimiento de temperatura y avenamiento eficaz de los suelos. Una manera de construir que exigía un profundo conocimiento de las particularidades del terreno y de las posibilidades de la técnica de mampostería en seco o de piedra seca.

Las acequias para regar, unas veces, y para desviar el agua de escorrentía, en la mayor parte de los casos, muestran el interés del agricultor por incrementar la productividad y asegurar la conservación del suelo, pero además nos informan de la técnica y cultura del grupo que las construyó. Por ejemplo, Pérez Carazo (2008) diferencia claramente en Camero Viejo las acequias de origen árabe y cristiano. En definitiva, en el paisaje e infraestructuras asociadas se puede leer a la vez el entramado de hechos y fenómenos visibles y las relaciones funcionales que han existido entre ellos a lo largo del tiempo, por lo que constituyen un patrimonio cultural de un valor irrenunciable.

\subsection{Función estética}

La consideración del espacio rural como recurso turístico se fundamenta, en gran medida, en los atractivos inherentes a su paisaje, por su singular encanto y belleza (Bielza, 1999; Cánoves et al., 2006). Aunque la belleza de un paisaje tiene mucho de emocional (Lowenthal, 1978), es necesario admitir que para muchas personas algunas laderas abancaladas tienen un gran atractivo. Biarge (2009) señala la alta valoración que reciben los paisajes abancalados del Parque Nacional de Ordesa y Monte Perdido (Pirineo Central), siendo uno de los principales atractivos para los visitantes del Parque. Jiménez Olivenza (1989-90) incluye las laderas de terrazas agrícolas de Sierra Nevada (Sistema Penibético) entre los paisajes más valorados, por su alta diversidad y belleza. Ocaña et al. (2004) indican que en la Axarquía malagueña los paisajes con estructura compleja, formada por un mosaico de manchas con vegetación natural alternando con otras manchas de cultivos de cítricos y aguacates en terrazas agrícolas, cuentan con la preferencia de los usuarios; los muros de piedra seca de las terrazas están construidos con materiales extraídos del terreno, aportando una perfecta 
integración visual en el entorno. Sayadi et al. (2009) señalan, al estudiar los paisajes de la Alpujarra granadina, las preferencias de los turistas por las laderas con bancales cultivados frente a las áreas con campos abandonados y vegetación natural.

Algunas laderas abancaladas constituyen áreas preferentes para la localización de segundas residencias, especialmente en las proximidades de grandes aglomeraciones urbanas y de espacios turísticos. Así ocurre, por ejemplo, en los Montes de Málaga por su cercanía a la Costa del Sol (Ocaña et al., 2004) a semejanza de lo que ocurre en los Pre-Alpes franceses por su proximidad a la costa azul (Réparaz, 1992).

\section{INICIATIVAS PARA LA CONSERVACIÓN DE LAS TERRAZAS AGRÍCOLAS}

Como consecuencia del abandono agrícola los bancales y sus paisajes están experimentando un importante proceso de degradación. El desmoronamiento de los muros externos, la pérdida de funcionalidad de las acequias y la invasión de los matorrales ponen en peligro la conservación de los suelos más fértiles de la montaña, y la pérdida de un paisaje que constituye un recurso esencial para la actividad turística y la economía de estas áreas. La desaparición del paisaje de bancales impide también la comprensión de la historia de los usos del territorio, pero sobre todo implica la pérdida de un patrimonio natural y cultural acumulado durante siglos, con destacadas potencialidades de producción que serán necesarias para las generaciones venideras (Frapa, 1984).

Consciente de esta situación, la Unión Europea ha intensificado los vínculos entre las políticas agrícola, ambiental y cultural, incluyendo los paisajes aterrazados en el Plan de Desarrollo Rural 2007-2013, en el Plan de Acción de Biodiversidad para la Agricultura y en la Estrategia Temática de Protección del Suelo. Además, considera también importante el apoyo a las Áreas Menos Favorecidas y a los Espacios Agrarios de Alto Valor Natural, en numerosas ocasiones abancalados, para que mantengan paisajes escénicos y hábitats valiosos a nivel ambiental.

También el "Convenio Europeo del Paisaje" abre la oportunidad de incrementar la defensa del paisaje. La Estrategia Territorial para la Protección del Suelo incluye como objetivo prioritario la protección y mantenimiento de las áreas aterrazadas, con el convencimiento de que sin suelo en las laderas no hay flora ni fauna que proteger. Paralelamente, iniciativas de desarrollo rural impulsadas por la Unión Europea como Mediterrinage tienen como objetivo optimizar el aprovechamiento de las terrazas agrícolas, combinando funciones productivas y recreativas (Rubio-Barquero et al., 2010). Desde la Unión Europea, en el marco del Programa Interreb IIIB: Espacio alpino, se impulsó en 2005 el proyecto ALPTER (Terraced landscapes in the alpine arc), que persigue entre sus objetivos evitar el abandono de áreas agrícolas aterrazadas en los Alpes mediante su valorización (producción primaria y turismo). El proyecto se desarrolló en ocho regiones alpinas de Italia (Venecia, Milán, Aoste y Génova), Francia (Niza), Austria, Eslovenia y Suiza. Entre los proyectos sobre terrazas agrícolas financiados por la Administración cabe destacar: PATTER, cuyo objetivo es localizar los bancales, definir su tipología y su estado de conservación, que se desarrolla en Mallorca, Niza y Génova; y TERRISC, que tienen como principal fin la prevención de riesgos naturales en laderas aterrazadas de Baleares, Portugal y SW de Francia. 
Desde el mundo académico y científico diversas instituciones y personas recuperan la vinculación entre funcionalidad y paisaje (ver, por ejemplo, Mathieu, 2006; Bertrand y Bertrand, 2006; Mata Olmo, 2007; Gómez-Moreno, 2008), bajo el prisma de que el mantenimiento de muchos paisajes sólo es posible si éstos cumplen funciones muy diversas, como ocurre con las terrazas agrícolas. Los procesos culturales, los fenómenos demográficos y económicos que indujeron al desarrollo agrario tradicional y generaron un paisaje ambiental y estético valioso han cambiado bruscamente en las últimas décadas, como nunca antes había ocurrido. El abandono rural y la pérdida cultural asociada son difíciles de evitar. Pero si tratamos de mantener ese paisaje, caben dos alternativas: dejar que los bancales se degraden totalmente o intentar darles alguna función, valorizarlos en la medida de lo posible, es decir, emprender un conjunto de acciones destinadas a incrementar sus prestaciones en términos ambientales, económicos y culturales.

Si se elige la segunda opción, conocemos ya la capacidad de los bancales para retener suelo y humedad y su más probada aptitud para el cultivo durante siglos. Pero las laderas abancaladas tienen también un indudable atractivo para viajeros y turistas. El turismo puede llevar a la alteración irreversible del paisaje, mediante la urbanización y la carencia de una planificación sensata, o bien puede contribuir con sus ingresos a cierta forma de mantenimiento del paisaje, aún cambiando parcialmente la economía agraria tradicional por otra de servicios y creando un mundo rural con apariencia de museo libre (De Aránzabal et al., 2002). El turismo de naturaleza y el cultural necesitan la participación de las comunidades locales. Estas son imprescindibles para conservar la naturaleza y para posibilitar un turismo compatible -posiblemente necesario- con la conservación del paisaje. La consideración de la interdependencia entre socioeconomía y paisaje es necesaria para la protección de las laderas abancaladas y del paisaje mediterráneo en general, lo que obliga a implicar a las comunidades locales y a las administraciones (Pineda, 2007).

Existen ya antecedentes sobre conservación de bancales y estimación de los costes, tanto en las montañas de Perú (Llerena et al., 2004), como en la India (Sharda y Dhyani, 2004) o en el Levante español y Mallorca (Reynes, 2002). Las obras de reconstrucción de terrazas han tenido por objeto la conservación del suelo, su puesta en cultivo y la recuperación de espacios de alto valor patrimonial y cultural. El elevado coste de la mano de obra y las dificultades para mecanizar tales trabajos son factores que hacen que el sector público sea el que se encargue de los proyectos de reconstrucción. Por otro lado, la gran extensión que ocupan las laderas abancaladas exige discriminar áreas de actuación en función de su interés para distintos usos (productivo, cultural, ambiental...), accesibilidad y grado de conservación. En este sentido, resulta muy útil el diseño de una metodología específica de escalas de calidad para la conservación de las unidades de paisaje (Romero-Martín et al., 2004).

\section{CONCLUSIONES}

Las laderas abancaladas ocupan grandes extensiones en las montañas españolas, especialmente en las mediterráneas. La construcción de bancales fue una respuesta frente a la erosividad de la lluvia, la escasez de tierras llanas y la necesidad de roturar las laderas para alimentar a la población. Durante siglos mantuvieron un equilibrio entre los balances económico, social y ambiental, claves utilizadas en la actualidad para definir el desarrollo sostenible del territorio 
(Comisión Europea, 2004). Desde hace algunas décadas, ese paisaje sufre procesos de marginación socioeconómica, degradación y tiende -en no pocos casos- a desaparecer.

Sin embargo, las terrazas agrícolas constituyen un paisaje-recurso, con una alta potencialidad para el desarrollo sostenible en muchas áreas de la montaña mediterránea, como consecuencia de su carácter multifuncional. Los bancales tienen capacidad para producir alimentos para las personas y para la ganadería, para diversificar las actividades económicas, estimular el turismo rural, fomentar la inversión privada y generar empleo (Vanslembrouk et al., 2005; Castex y Dagorne, 2007). El mantenimiento de las terrazas sirve también para evitar la erosión del suelo, regular la dinámica hidrológica de las laderas y ralentizar el aterramiento de embalses (García-Ruiz y López Bermúdez, 2009). El cultivo de algunas terrazas y el aprovechamiento ganadero contribuyen a fragmentar el paisaje con efectos positivos en la prevención de incendios forestales y en la disminución de la velocidad de propagación de los fuegos, si los hubiera (Lasanta et al., 1996); también contribuyen a la conservación de la flora y fauna asociadas a paisajes humanizados (Suárez-Seoane et al., 2002).

El mantenimiento, recuperación en algunos casos, y la reintegración de las terrazas agrícolas en la economía de montaña debe considerarse como un objetivo prioritario de las políticas públicas, por sus beneficios económicos y ecológicos. Además, conviene no olvidar que los paisajes agrarios constituyen el principal patrimonio histórico y cultural de muchos pueblos y un recurso básico para el desarrollo territorial y la calidad de vida de la población próxima, pero también de la vinculada. De ahí, que en diferentes regiones de Suiza, Francia, Italia y España se hayan impulsado recientemente planes para conservar las laderas de bancales (Asins, 2009).

\section{AGRADECIMIENTOS}

Este trabajo se ha realizado en el marco de los proyectos de investigación: INDICA (CGL2011-27753-CO2-01-02): Indicadores geomorfológicos de los cambios de uso del suelo en áreas de montaña submediterránea, e HIDROCAES (CGL2011-27574-CO2-02): Impactos hidrológicos del cambio global en España, 2, financiados por la Dirección General de Investigación y Gestión del plan nacional de I+D+i, del Gobierno de España. Ha contado también con el apoyo de la Diputación General de Aragón al Grupo Consolidaddo "Geomorfología y Cambio Global”.

\section{BIBLIOGRAFÍA}

ALOMAR, G. y BARDI, G. (2007): Prevención y lucha contra los incendios forestales: El uso del ganado en los campos abancalados de la Serra de Tramuntana. Actas de las Jornadas sobre terrazas y prevención de riesgos naturales. Consell de Mallorca. Departament de Medi Ambient: 245-251.

ALPTER (2005-2007): Terraced landscapes in the alpin arc. European Commission, Project. ANGLADA, S., BALCELLS, E., CREUS, J., GARCÍA-RUIZ, J.M., MARTÍ, C. y PUIGDEFÁBREGAS, J. (1980): La vida rural en la montaña española. Orientaciones para su promoción. Instituto de Estudios Pirenaicos: 133 pp, Jaca. 
ARBELO, C.D., RODRÍGUEZ-RODRÍGUEZ, A., GUERRA, J.A., MORA, J.L., NOTARIO, J.S. y FUENTES, F. (2006): Soil degradation processes and plant colonization in abandoned terraced fields overlying pumice tuffs. Land Degradation and Development, 17: 571-588.

ARNAEZ, J., LASANTA, T., ORTIGOSA, L. y RUIZ-FLAÑO, P. (1990): L'abandon de l'espace agricole dans la montagne submediterraneenne espagnole: Pyrénées et Système Iberique. Revue Géographique des Pyrénées et du Sud-Ouest, 61(2) : 237-253.

ARNÁEZ, J., ORTIGOSA, L. y OSERÍN, M. (1993): Erosión hídrica superficial en campos abancalados del Sistema Ibérico riojano (valles del Leza y Jubera). Geographicalia, 30, pp. 33-45.

ARNÁEZ, J., ORTIGOSA, L., LLORENTE, J.A., OSERÍN, M. y LARREA, V. (2009). Gestión del territorio y erosión de suelos en Cameros. En Lasanta, T. y Arnáez, J. (Eds): Gestión, usos del suelo y paisaje en Cameros (Sistema Ibérico). Universidad de La Rioja, pp. 145-164, Logroño.

ARNÁEZ, J., LASANTA, T., ERREA, M.P. y ORTIGOSA, L. (2011): Land abandonment, landscape evolution, and soil erosion in a Spanish Mediterranean mountain region: The case of Camero Viejo. Land Degradation \& Development, 22: 537-550.

ASCASO, J., FERRER, C. y MAESTRO, M. (1996): Valoración estacional y anual de los recursos pastables en el Maestrazgo de Castellón. Actas de la XXXVI Reunión Científica de la S.E.E.P.: 161-165.

ASINS, S. (2006): Linking historical Mediterranean terraces with catchment, harvesting and distribution structures: En J.P. Morel et al., (Eds): The Archeology of crop and gardens. Ediplugia, pp. 21-40, Bari (Italia).

ASINS, S. (2007): Los aterrazamientos mediterráneos. Paradigma ambiental-agro-cultural. Cuadernos de la Sostenibilidad y Patrimonio Natural, 11: 81-91.

ASINS, S. (2009): El paisaje agrario aterrazado. Diálogo entre el hombre y el medio en Petrer (Alicante). Publicaciones de la Universidad de Valencia: 359 pp., Valencia.

BALCELLS, E. (1985): Ordesa - Viñamala. MAPA - ICONA, 127pp., Madrid,

BERTRAND, C y BERTRAND, G. (2006): Geografía del medio ambiente. El sistema GTP: Geosistema, territorio y paisaje. Ediciones de la Universidad de Granada, Granada.

BIARGE, F. (2009): Sobrarbe. Letra menuda. Diputación de Huesca: 322 pp., Huesca.

BIELZA, V. (1999): Desarrollo sostenible, turismo rural y parques culturales. Cuadernos de Investigación Geográfica, 25: 125-137.

BLANC, J.F. (1984): Paysages et paysans des terrasses de l'Ardéche. Annonay, 321pp., Le Cleylard,

BOSQUE MAUREL, J. (1968): Tradición y modernidad en las Alpujarras granadinas. Aportación española al XXI Congreso Geográfico Internacional. CSIC, Madrid.

CALVO PALACIOS, J.L. (1977): Los Cameros. De región homogénea a espacio-plan. Instituto de Estudios Riojanos, 2 vols., Logroño.

CÁNOVES, G., VILLARINO, M. y HERRERA, L. (2006): Políticas públicas, turismo rural y sostenibilidad: difícil equilibrio. Boletín de la Asociación de Geógrafos Españoles, 41: 199-217.

CASTEX, J.M. y DAGORNE, A. (2007): Quel avenir pour les espaces en terrasses sur le pourtour de la Méditerranée ? Presentations fron the Alpter international conference on terraced landscapes in Venice. $22^{\text {nd }}$ to the $24^{\text {th }}$ of February, 2007. Venice. 
CERDÀ I BOLINCHES, A. (1994): Arroyada superficial en terrazas de cultivo abandonadas: el caso del País Valenciano. Cuadernos de Geografía, 56: 135-154.

COMISIÓN EUROPEA (2004): Environment and forestry biodiversity action Plan for Agricultura Implementation report. Agriculture Directorate General. Directorate F-Horizontal aspects of rural development; SAPARD, F.1. Document.

COTS-FOLCH, R., MARTÍNEZ-CASASNOVAS, J.A. y RAMOS, M.C. (2006): Land terracing for new vineyard plantations in the north-eastern Spanish Mediterranean region: Landscape affects of the EU Council Regulation policy for vineyards' restructuring. Agriculture, Ecosystems and Environment, 115: 88-96.

CREUS, J. (1978): La transición climática altoaragonés. Estudios Geográficos, 153: 495517.

DE ARÁNZABAL, I., AGUILERA, P., RESCIA, A., SCHMITS, M.F. y PINEDA, F.D. (2002): Spatial analysis of impacts and potentialities for leisure activities. Bases for territorial ordination of tourism uses. En: BREVIA, C. A. y PASCOLO, P. (Eds): Management Information Systems. Incorporating GIS and Remote Sensing. WIT Pres, Southampton.

DELGADO VIÑAS, C., GIL DE ARRIBAS, C., HORTELANO MÍNGUEZ, L.A. y PLAZA GUTIÉRREZ, J.I. (2010): La montaña cantábrica oriental. Dinámica socioeconómica, patrimonio ecocultural y desarrollo territorial. Ediciones de Librería Estudio: 371 pp., Santander.

DUNJÓ, G., PARDINI, G. y GISPERT, M. (2003): Land use change effects on abandoned terraced soils in a Mediterranean catchment, NE Spain. Catena, 32: 23-37.

ERREA, M.P., LASANTA, T., ARNÁEZ, J., ORTIGOSA, L., RUIZ-FLAÑO, P. y OSERÍN, M. (2009): Cambios en el paisaje de Cameros durante la segunda mitad del siglo XX. En: Lasanta, T. y Arnáez, J., Eds.: Gestión, usos del suelo y paisaje en Cameros (Sistema Ibérico, La Rioja). Universidad de La Rioja e Instituto de Estudios Riojanos: 165-190 pp., Logroño.

EUROPEAN COMMISSION (2005): Agri-environment Measures: Overiew on General Principles, Types of Measures, and Application. Directorate General for Agroculture and Rural Developemnt.

FRAPA, P. (1984): Les terrasses de culture entre le passé et l'avenir. Forêt Méditerranéenne, t. VI, $n^{\circ} 2: 129-130$.

GALLEGO-FERNÁNDEZ, J.B., GARCÍA-MORA, M.R. y GARCÍA-NOVO, F. (2004): Vegetation dynamics of Mediterranean shrublands in former cultural landscape at Grazalema mountains, South Spain. Plant Ecology, 172: 83-94.

GARDNER, R.A.M. y GERRARD, A.J. (2003): Runoff and soil erosion on cultivated rainfed terraces in the Middle Hills of Nepal. Applied Geography, 23(1): 23-45.

GARCÍA-RUIZ, J.M., LASANTA, T. y SOBRÓN, I. (1988): Problemas de evolución geomorfológica en campos abandonados: el valle del Jubera (Sistema Ibérico). Zubía, 6: 99-114.

GARCÍA-RUIZ, J.M. y LÓPEZ-BERMÚDEZ, F. (2009): La erosión del suelo en España. Sociedad Española de Geomorfología, 441pp., Zaragoza.

GARCÍA-RUIZ, J.M. y LANA-RENAULT, N. (2011). Hydrological and erosive consequences of farmland abandonment in Europe, with special reference to the Mediterranean region-A review. Agriculture, Ecosystem \& Environment, 140: 317-338. 
GÓMEZ-MORENO, M.L. (2008): Los retos de la gestión del paisaje en la montaña mediterránea: relación entre tamaño, rentabilidad de la explotación y paisaje. Cuadernos Geográficos, 43: 327-348.

GÓMEZ URDAÑEZ, J.L. (1987): Subsistencia y descapitalización en el Camero Viejo al final del Antiguo Régimen. Cuadernos de Investigación Histórica, Brocar, 12: 103-140.

GONZÁLEZ BERNÁLDEZ, F. (1981): Ecología y paisaje. H. Blume Ediciones: 250 pp., Madrid.

GRASHOF-BOKDAM C.J. y VAN LANGEVELDE, F. (2004): Green veining: landscape determinats of biodiversity in European agricultural landscapes. Landscape Ecology, 20: 417-439.

GRIMALT, M. y BLÁZQUEZ, M. (1989): El mapa de marjades de la Serra de Tramuntana de Mallorca. Treballs de Geografía, 42: 43-47.

GRIMALT, M., BLAZQUEZ, M., y RODRÍGUEZ, R. (1992): Physical factors, distribution and present land-use of terraces in the Tramuntana Range. Pirineos, 139: 15-25.

INBAR, M. y LLERENA, C.A. (2000): Erosion processes in High Mountain agricultural terraces in Perú. Mountain Research and Development, 20(1): 72-79.

JIMÉNEZ OLIVENZA, Y. (1989-90): Cambios medioambientales que suceden al abandono de los campos de cultivo en terrazas: La acequia de Cachariche. Cuadernos Geográficos de la Universidad de Granada, 18-19: 5-45.

JIMÉNEZ OLIVENZA, Y. y PORCEL, L. (2008): Metodología para el estudio evolutivo del paisaje: Aplicación al espacio protegido de Sierra Nevada. Cuadernos Geográficos, 43: 151-179.

JOY, J. y MEDRANO, A. (2007): Valoración de terrazas frente a incendios forestales en la CAIB. Actas de las Jornadas sobre terrazas y prevención de riesgos naturales. Consell de Mallorca. Departament de Medi Ambient, 239-243 pp.

LASANTA, T. (1989): Evolución reciente de la agricultura de montaña: El Pirineo aragonés. Geoforma Ediciones: 220 pp., Logroño.

LASANTA, T. (1990): Distribución espacial de modelos de campos en el Alto Gállego. En: Homenaje a Amigos del Serrablo. Diputación de Huesca: 153-167, Huesca.

LASANTA, T. (1996): El proceso de marginación de tierras en España. En: Lasanta, T. y García-Ruiz, J.M. (Eds.): Erosión y recuperación de tierras en áreas marginales, Instituto de Estudios Riojanos y Sociedad Española de Geomorfología: 7-31, Logroño.

LASANTA, T. (1997): La transformación del paisaje de montaña media por la actividad agrícola en relación con las actividades tradicionales. En: García-Ruiz, J.M. y LópezGarcía, P. (Eds.): Acción humana y desertificación en ambientes mediterráneos. Consejo Superior de Investigaciones Científicas: 145-172, Zaragoza.

LASANTA, T. (2009): La ganadería en Cameros: entre la adaptación a los recursos y la dependencia del exterior. En: Lasanta, T. y Arnáez, J. (Eds.): Gestión, usos del suelo y paisaje en Cameros (Sistema Ibérico, La Rioja). Universidad de La Rioja e Instituto de Estudios Riojanos: 191-222, Logroño.

LASANTA, T. (2010): Evolución regional y dinámica del paisaje en La Rioja (1950-2010). Zubía, 28: 49-88. 
LASANTA, T., ARNÁEZ, J., ORTIGOSA, L. y RUIZ-FLAÑO, P (1996): Consecuencias geoecológicas del abandono agrícola en Cameros Viejo (Sistema Ibérico). Zubía, monográfico, 8: 61-85.

LASANTA, T., ARNÁEZ, J., OSERÍN, M. y ORTIGOSA, L. (2001): Marginal lands and erosion in terraced fields in the Mediterranean mountains. Mountain Research and Development, 21(1): 69-76.

LASANTA, T., GONZÁLEZ-HIDALGO, J.C., VICENTE-SERRANO, S. y SFERI, E. (2006): Using landscape ecology to evaluate an alternative management scenario in abandoned Mediterranean mountainous areas. Landscape and Urban Planning, 78: 101-114.

LASANTA, T., ARNÁEZ, J., ERREA, M.P., ORTIGOSA, L. y RUIZ-FLAÑO, P. (2009a): Mountain pastures, environmental degradation, and landscape remediation: The example of a Mediterranean policy initiative. Applied Geography, 29: 308-319.

LASANTA, T., ARNÁEZ, J., ORTIGOSA, L., OSERÍN, M. y RUIZ FLAÑO, P. (2009b): Espacio agrícola y agricultura en Cameros a mediados del siglo XX. En: Lasanta, T. y Arnáez, J. (Eds.). Gestión, usos del suelo y paisaje en Cameros (Sistema Ibérico, La Rioja). Universidad de La Rioja e Instituto de Estudios Riojanos, 373 pp., Logroño.

LATRON, J. (1991): Etude des modifications de la dynamique hydromorphologique liées à la mise en terrasses et à leur abandon (Bassin de Cal Parisa, Pyrénées Catalanes). Strasbourg (France), Memoire D.E.U.S. Environment. Université Louis Pasteur.

LESSCHEN, J.P., CAMMERAAT, L.H. y NIEMAN, T. (2008): Erosion and terrace failure due to agricultural land abandonment in a semi-arid environment. Earth Surface Processes and Landforms, 33: 1574-1584.

LLERENA, C., INBAR, M. y BENAVIDES, M. (2004): Conservación y abandono de andenes. Universidad Nacional Agraria de la Molina, Lima.

LLORENS, P., LATRON, J. y GALLART, F. (1992): Analysis of the role of agricultural abandonment terraces on the hydrology and sediment dynamics in a small mountainous basin. Pirineos, 139: 27-46.

LOWENTHAL, D. (1978): Finding valued landscapes. Progress in Human Geography, 2-3: 373-418.

MAISO, E. y LASANTA, T. (1990): El espacio agrario en el valle del Linares: características y utilización reciente. Berceo, 118: 53-62.

MANDER, Ü, MIKK, M. y KÜLVIK, M. (1999): Ecological and intensity agriculture as contribution to landscape and biological diversity. Landscape and Urban Planning, 46: 169-177.

MATA OLMO, R. (2007): El paisaje, patrimonio y recurso para el desarrollo territorial sostenible. Conocimiento y acción pública. Arbor, 729: 155-172.

MATHIEU, N. (2006): La Géographie rurale francaise face à la l'utopie du développement durable. Quelles réactions, quelles perspectives. Boletín de la Asociación de Geógrafos Españoles, 41: 39-67.

MOREIRA, F., QUEIROZ, A.I. y ARONSON, J. (2006): Restoration principles applied to cultural landscapes. Journal for Nature Conservation, 14: 217-224.

MURISIER, F. (1981): La culture de la vigne en banquettes. La situation en Suisse romande. Revue Suisse de Viticulture, Arboriculture et Horticulture 13 (2): 77-82. 
OCAÑA, M.C., GÓMEZ-MORENO, M.L. y BLANCO SEPÚLVEDA, R. (2004): Las vistas como recurso territorial. Ensayo de evaluación del paisaje visual mediante un SIG. Imalgraf Impresores, 172 pp., Málaga.

PALACIOS CUESTA, R. (2009): Caracterización del sistema productivo tradicional y evolución actual en el término de Peroblasco (Sistema Ibérico. La Rioja. Munilla). Memoria de Investigación. Universidad de La Rioja, Logroño.

PÉREZ CARAZO, P. (2008): Santa María de Herce y su abadengo en la Edad Media. Universidad de La Rioja - Instituto de Estudios Riojanos, Logroño.

PÉREZ CUEVA, A.J. (1985): Geomorfología del sector ibérico valenciano entre los ríos Mijares y Turia. Tesis Doctoral. Universidad de Valencia: 653 pp., Valencia.

PÉREZ CUEVA, A.J. y RECATALÁ, M.T. (1990): Degradación de medios agrícolas en montaña por precipitaciones: el valle de Ayora. IVEI, 88 pp., Valencia.

PETANIDOU, T., KIZOS, T. y SOULAKELLIS, N. (2008): Socioeconomic dimensions of changes in the agricultural landscape of the Mediterranean Basin: A case study of the abandonment of cultivation terraces on Nisyros Island, Greece. Environmental Management, 41: 250-266.

PINEDA, F. D. (2007): Conservación del paisaje mediterráneo. Contexto actual y perspectivas. Cuadernos de la Sostenibilidad y Patrimonio Natural, 11: 101-112.

POYATOS, R., LATRON, J. y LLORENS, P. (2003): Land-use and land cover change after agricultural abandonment. The case of a Mediterranean Mountain Area (Catalan PrePyrenees). Mountain Research and Development, 23 (4): 52-58.

REPARAZ, G.A. (1992): Le recul de l'espace agro-pastoral dans les Prealpes du Sud et ses conséquences sur le paysage de la moyenne montagne. Pirineos, 139 : 47-66.

REYNES, A. (2002): Llibre de la pedra en sec. Consell de Mallorca. Rey Sol S.A. Ed., Mallorca.

RODRÍGUEZ AIZPEOLEA, J. (1990): Evolució i situació actual dels bancals abandonats en el Parc Natural del Montgó. Aguaits, 5: 19-54.

RODRÍGUEZ AIZPEOLEA, J., PÉREZ BADÍA, R. y CERDÀ BOLINCHES, A. (1991): Colonización vegetal y producción de escorrentía en bancales abandonados: Vall de Gallinera, Alacant. Cuaternario y Geomorfología, 5: 119-130.

RODRÍGUEZ AIZPEOLEA, J. (1992): Distribució espacial i evolució da l'agricultura a la vall d'Ebo. III Congrès d'Estudis de la Marina Alta. Institut de Cultura "Juan Gil-Albert" -IECMA: 545-553, Alicante.

RODRÍGUEZ-AIZPEOLEA, J. y LASANTA, T. (1992): Los bancales en la agricultura de montaña mediterránea: una revisión bibliográfica. Pirineos, 139: 105-123.

ROMERO-MARTÍN, L., RUIZ-FLAÑO, P. y HERNÁNDEZ-CALVENTO, L. (2004): Diagnóstico y calidad para la conservación de los espacios agrícolas abancalados. Propuesta metodológica para la cuenca del Guiniguada (Gran Canaria, Islas Canarias). Geographicalia, 45: 113-127.

RON, Z. (1966): Agricultural terraces in the Judean Mountains. Israel Exploration Journal, 16: $111-122$.

RUBIO-BARQUERO, L.M., GÓMEZ-MORENO, M.L. y BLANCO-SEPÚLVEDA, R. (2010): Sostenibilidad y orientación de las explotaciones en terrazas de cultivo en regadío. Papeles de Geografía, 51-52: 257-267. 
RUECKER, G., SCHARD, P., ALCUBILLA, M. y FERRER, C. (1998): Natural regeneration of degraded soils and site changes on abandoned agricultural terraces in Mediterranean Spain. Land Degradation and Development, 9: 179-188.

RUIZ-FLAÑO, P., LASANTA, T., ARNÁEZ, J., ORTIGOSA, L. y OSERÍN, M. (2009): El proceso de abandono del espacio agrícola en Cameros. En: Lasanta, T. y Arnáez, J. (Eds.). Gestión, usos del suelo y paisaje en Cameros (Sistema Ibérico, La Rioja). Universidad de La Rioja e Instituto de Estudios Riojanos: 109-126, Logroño.

SANTANA, V.M., JAIME BAEZA, M., MARRAS, R.H. y VALLEJO, V.R. (2010): Old field secondary succession in SE Spain: can fire diver it? Plant Ecology, 211: 337-349.

SAYADI, S., GONZÁLEZ-ROA, M.C. y CALATRAVA-REQUENA, J. (2009): Public preferences for landscape features: The case of agricultural landscape in mountainous Mediterranean areas. Land Use Policy, 26: 334-344.

SANTOS SOLLA, J.M. (1992): Geografía de la vid y el vino en Galicia. Excma. Diputación Provincial de Pontevedra, 270 pp., Vigo.

SHARDA, V.N. y DHYANI, B.L. (2004): Economic analysis of conventional and conservation bench terrace systems in a sub-humid climate. Transactions of the ASAE, 47(3): 711-720.

SUÁREZ-SEOANE, S., OSBORNE, P.E. y BAUDRY, J. (2002): Responses of birds of different biogeographic origins and habitat requirements land abandonment in Northern Spain. Biological Conservation, 105: 333-344.

TATONI, T., MAGNIN, F. BONIN, G. y VADOUR, J. (1994): Secondary successions on abandoned cultivation terraces in calcareous Provence. I- Vegetation and soil. Acta Oecologica, 15(4): 431-447.

TURKELBOOM, F., POESEN, J. y TREBAIL, G. (2008): The multiple land degradation effects caused by land-use intensification in tropical steeplands: A catchment study from northern Thailand. Catena, 75(1): 102-116.

VANSLEMBROUCK, I., VAN HUYCEMBROECK, G. y VAN MEENSEL, J. (2005): Impact of agriculture on rural tourism: a hedonic pricing approach. Journal of Agriculture Economics, 56: 17-30.

VICENTE-SERRANO, S., LASANTA, T. y ROMO, A. (2000): Influencia de la ganadería en la evolución del riesgo de incendio en función de la vegetación de un área de montaña: El ejemplo del Valle de Borau. Geographicalia, 38: 33-57.

WINTER-NELSON, A. y AMEGBETO, K. (1998): Option values to conservation and agricultural price policy: Application to terrace condition in Kenya. American Journal of Agricultural Economics, 80(2): 409-418. 